\title{
SRESLi: SMART RENEWABLE ENERGY STREET LIGHTING SYSTEM
}

Fabiana Cañipa, Fabio Arnez, Omar Ormachea, Alex Villazón, Armando Rivero y Gian Carlo Dozio and E. Escobar

\begin{abstract}
Conventional street lighting systems do not allow controlling the light intensity depending on the traffic of pedestrians or vehicles, only operate in two automatic modes (on/off) according to the availability of daylight and consume enormous amounts of electric energy. In this article, we describe the design, development and implementation of a new intelligent street lighting system that is based on LED technology, an energy-efficient embedded wireless control device (hardware) designed from scratch, and photovoltaic solar energy. The embedded device includes specialized firmware and an energy-efficient wireless communication protocol, that allows to form a network of infrared sensors to detect pedestrians and vehicles, so as to control and dim the LED luminaires. We implemented a pilot system in a back road of the campus of Universidad Privada Boliviana, in the city of Cochabamba, Bolivia, where energy consumption measurements confirm energy savings of $72.8 \%$ thanks to the developed intelligent control system.
\end{abstract}

Keywords: Street Lighting System, Photovoltaic System, Intelligent Wireless Control System, Energy Efficiency.

DOI: 10.23881/idupbo.019.1-1i 